nephron

Practice
Nephron 2018;138:222-228

DOI: $10.1159 / 000481892$
Received: July 19, 2017

Accepted after revision: September 28, 2017

Published online: October 19, 2017

\title{
Urine Ammonium, Metabolic Acidosis and Progression of Chronic Kidney Disease
}

\author{
Negiin Pourafshar ${ }^{a}$ Shirin Pourafshar ${ }^{a} \quad$ Manoocher Soleimani $^{b, c}$ \\ ${ }^{a}$ Department of Medicine at University of Virginia, Charlottesville, VA, USA; ${ }^{\text {b }}$ Department of Medicine, University of \\ Cincinnati, Cincinnati, $\mathrm{OH}, \mathrm{USA}^{\circ}{ }^{\mathrm{C}}$ Department of Medicine Services, Veterans Medical Center, Cincinnati, $\mathrm{OH}, \mathrm{USA}$
}

\section{Keywords}

Urine ammonium · Acidosis · Chronic kidney disease

\begin{abstract}
The metabolism of a typical Western diet generates $50-100$ $\mathrm{mEq}$ of acid $\left(\mathrm{H}^{+}\right)$per day, which must be excreted in the urine for the systemic acid-base to remain in balance. The 2 major mechanisms that are responsible for the renal elimination of daily acid under normal conditions are ammonium $\left(\mathrm{NH}_{4}{ }^{+}\right)$ excretion and titratable acidity. In the presence of systemic acidosis, ammonium excretion is intensified and becomes the crucial mechanism for the elimination of acid. The impairment in $\mathrm{NH}_{4}{ }^{+}$excretion is therefore associated with reduced acid excretion, which causes excess accumulation of acid in the body and consequently results in metabolic acidosis. Chronic kidney disease (CKD) is associated with the impairment in acid excretion and precipitation of metabolic acidosis, which has an adverse effect on the progression of CKD. Recent studies suggest that the progressive decline in renal ammonium excretion in CKD is an important determinant of the ensuing systemic metabolic acidosis and is an independent factor for predicting the worsening of kidney function. While these studies have been primarily performed
\end{abstract}

\section{KARGER}

(c) 2017 S. Karger AG, Basel

E-Mail karger@karger.com

www.karger.com/nef in hypertensive individuals with CKD, a closer look at renal $\mathrm{NH}_{4}{ }^{+}$excretion in non-hypertensive individuals with CKD is warranted to ascertain its role in the progression of kidney disease.

(c) 2017 S. Karger AG, Basel

\section{Introduction}

The elimination of acid $\left(\mathrm{H}^{+}\right)$by kidney is the most crucial step in the maintenance of systemic acid-base homeostasis $[1,2]$. The renal excretion of acid $\left(\mathrm{H}^{+}\right)$is achieved by titratable acidity and ammonium $\left(\mathrm{NH}_{4}^{+}\right)$excretion, with the latter playing a critical role in acid-base balance, specifically when endogenous acid production is enhanced [3]. Metabolic acidosis is generated consequent to either enhanced production of endogenous acid or decreased excretion of acid by the kidney [4]. One major pathophysiologic state associated with metabolic acidosis is the chronic kidney disease (CKD), which is characterized by a gradual reduction in the number of functioning nephrons and impairment in acid excretion, eventually culminating in significant retention of endogenous acid $[5,6]$. The total ammonium excretion begins to fall when

Dr. Negiin Pourafshar Department of Medicine University of Virginia Charlottesville, VA 22908 (USA)

E-Mail NP5G@hscmail.mcc.virginia.edu 
the glomerular filtration rate (GFR) drops below $40 \mathrm{~mL} /$ min (normal values are $85-120 \mathrm{~mL} / \mathrm{min}$ ) $[1,2]$, which is a consequence of few functioning nephrons [7]. As a result, CKD leads to the retention of hydrogen ions $[1,5,8$, 9]. In addition to the fall in ammonium excretion, reduced excretion of titratable acid such as phosphoric acid also may play a role in the pathogenesis of metabolic acidosis in patients with advanced kidney disease. Progressive metabolic acidosis and acidemia can develop and are very common with advancing stages of CKD [10].

Diet plays an important role in acid-base homeostasis, with phosphorus and sulfur content contributing to enhanced kidney acid excretion [11]. In a study by Lemann and Relman [12], the incremental excretion of sulfate equaled enhanced net acid excretion in healthy volunteers. Likewise, a similar phenomenon is observed with phosphorus excretion in healthy individuals. In contrast, CKD patients with declining kidney function lack this ability. These patients experience diminished excretion of different substances such as phosphorus, leading to the impairment of acid excretion in the form of reduced titratable acidity. In a study by Khairallah et al. [13], it was shown that the presence of metabolic acidosis in CKD is associated with the elevation of serum phosphate and augmented phosphaturia. The latter observation was thought to moderate the magnitude of hyperphosphatemia and help toward the worsening of metabolic acidosis in CKD. These findings do not conflict with other studies showing that with lower GFR, the net acid excretion is decreased and serum phosphorus concentration is increased. It is important to note that the presence of hyperphosphatemia can trigger the release of parathyroid hormone (PTH), which in turn may cause $\mathrm{HCO}_{3}{ }^{-}$wasting consequent to proximal renal tubular acidosis, thus contributing to the worsening of metabolic acidosis in CKD. To avoid these maladies, dietary phosphorus restriction is highly recommended in CKD. As such, foods and supplements with no or low amounts of inorganic phosphorus are recommended for those with CKD [14].

\section{Ammonium Generation and Excretion}

Ammonia $\left(\mathrm{NH}_{3}\right)$ is predominantly generated from the metabolism of glutamine in the kidney through the process of ammoniagenesis. Glutamine is synthesized in the liver and transported via circulation to kidney proximal tubule, where it is taken up by specific transporters [15]. Glutamine is the major precursor of the ammonia pro- duced during acidosis [16-18]. Data suggest that adaptation to metabolic acidosis is sustained by the induction of multiple enzymes and various transport systems, such as glutaminase and phosphoenolpyruvate carboxykinase [19].

Thereafter, glutamine is metabolized via mitochondrial phosphate - dependent glutaminase and glutamate dehydrogenase into $a$-ketoglutarate. The net effect of these processes is the generation of $\mathrm{NH}_{3}$ and $\mathrm{HCO}_{3}{ }^{-}$. The $\mathrm{NH}_{3}$ is either secreted into the lumen of proximal tubule, where it combines with $\mathrm{H}^{+}$(secreted via $\mathrm{H}^{+}$-ATPase) or is transported via the $\mathrm{Na}^{+} / \mathrm{H}^{+}$exchanger (NHE-3), which can function as a $\mathrm{Na}^{+} / \mathrm{NH}_{4}{ }^{+}$exchanger [20]. Under normal acid-base conditions, the glutamine nitrogen extraction by the kidney is greater than the amount of ammonia produced, thus indicating that nitrogen supplied by glutamine extraction is more than sufficient to account for ammonia production [17].

The $\mathrm{NH}_{4}{ }^{+}$is transported along the length of the proximal tubule to the medullary thick ascending limb, where it is absorbed into the medullary interstitium primarily via the apical $\mathrm{Na}-\mathrm{K}-2 \mathrm{Cl}$ cotransporter, with $\mathrm{NH}_{4}{ }^{+}$substituting for $\mathrm{K}^{+}$. The $\mathrm{NH}_{4}{ }^{+}$thus reabsorbed dissociates into $\mathrm{NH}_{3}$ (ammonia) and $\mathrm{H}^{+}$due to the less acidic milieu. The ammonia is then secreted into the lumen of the collecting duct, where it is trapped as an ammonium ion $\left(\mathrm{NH}_{4}^{+}\right)$by $\mathrm{H}^{+}$secreted through intercalated cells via $\mathrm{H}^{+}$ATPase (and $\mathrm{H}^{+} / \mathrm{K}^{+}$ATPase) $[21,22]$. Collecting duct $\mathrm{NH}_{4}{ }^{+}$excretion requires the presence of Rhesus protein, RhCG, which is detected on both the apical and basolateral membranes of the majority of cells of the distal convoluted tubule and intercalated cells of the connecting tubule and collecting duct $[15,22,23]$. Under normal conditions, RhCG is the major putative ammonia transporter expressed in the human kidney, and RhBG is expressed at below detectable levels. Excretion of ammonium by the kidney results in the generation of new $\mathrm{HCO}_{3}{ }^{-}$in the proximal tubule, which is transported to the blood via the basolateral $\mathrm{Na}^{+}: 3 \mathrm{HCO}_{3}{ }^{-}$cotransporter NBC-e1 (SLC4A4) [24, 25]. Several circulating hormones or factors such as angiotensin II, aldosterone, and blood potassium level regulate ammonia generation and excretion [26]. The schematic diagrams in Figure 1 depict the generation and excretion of ammonium in kidney tubules and their impact on bicarbonate generation and acid elimination. Figure 1a illustrates the generation of $\mathrm{NH}_{4}{ }^{+}$and $\mathrm{HCO}_{3}{ }^{-}$in the kidney proximal tubule and Figure $1 \mathrm{~b}$ shows the secretion of $\mathrm{NH}_{4}{ }^{+}$into the lumen of proximal tubule and its subsequent absorption and secretion in the thick ascending limb and medullary col- 
Fig. 1. Schematic diagrams depicting the generation and excretion of ammonium in the kidney. a illustrates the generation of $\mathrm{NH}_{4}{ }^{+}$and $\mathrm{HCO}_{3}{ }^{-}$in the kidney proximal tubule and $\mathbf{b}$ shows the secretion of $\mathrm{NH}_{4}{ }^{+}$ into the lumen of proximal tubule and its subsequent absorption and secretion in the thick ascending limb and medullary collecting duct, respectively.

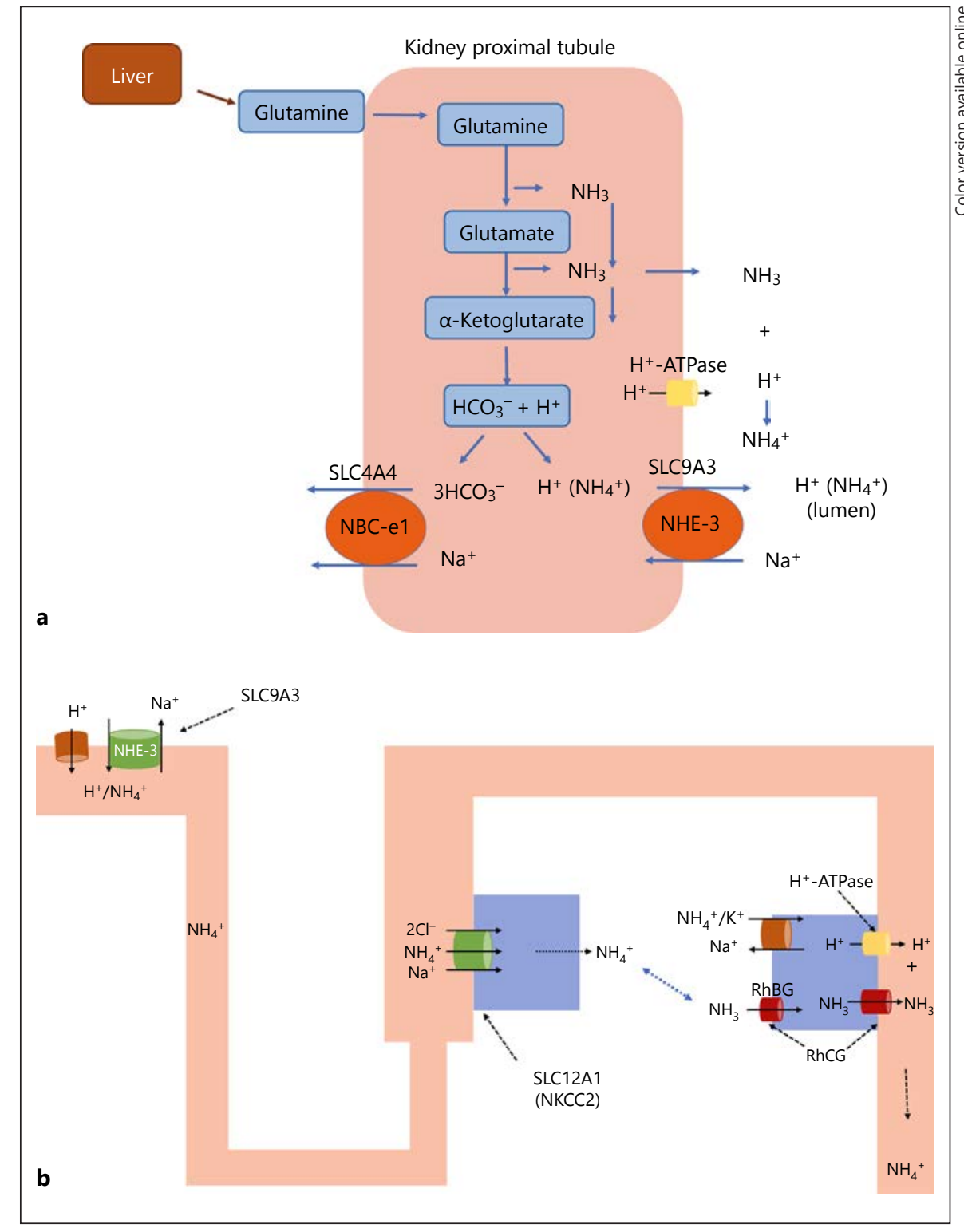

lecting duct, respectively. The most potent stimulator of $\mathrm{NH}_{4}{ }^{+}$generation and excretion is metabolic acidosis [17, 27].

\section{Metabolic Acidosis and CKD}

Chronic metabolic acidosis in patients with CKD is associated with multiple adverse outcomes, including bone resorption and osteopenia $[9,28]$, enhanced muscle protein catabolism $[6,29]$, aggravation of secondary hyperparathyroidism [30], endocrine disorders such as resistance to growth hormone and insulin, hypertriglyceride- mia $[6,29]$, hypotension, and constitutional symptoms such as malaise and weakness [5, 6]. Moreover, observational studies in patients with non-dialysis dependent CKD [31] and end-stage renal disease (ESRD) [32] have described a significant association of metabolic acidosis with higher mortality. Observational studies in patients with non-dialysis dependent CKD have found that lower serum bicarbonate concentrations, higher net endogenous acid production, high dietary acid load, and inability to excrete acid are all associated with a higher risk of progressive renal function loss $[33,34]$.

The exact prevalence of metabolic acidosis in patients with CKD remains unknown. The analysis of the third 
annual National Health and Nutrition Examination Survey (NHANES III; 1988-1994) revealed a detectable decrease in plasma bicarbonate concentration, with GFR less than $20 \mathrm{~mL} / \mathrm{min}[35,36]$. Previous studies suggested that approximately 300,000-400,000 individuals in the United States might have metabolic acidosis associated with CKD [36]. In a separate analysis of the NHANES database, Eustace et al. [10] estimated that 300,000 subjects have plasma bicarbonate concentrations less than 22 $\mathrm{mEq} / \mathrm{L}$. An analysis of published articles with reported acid-base parameters of apparently healthy individuals at different age groups [37] showed that the progression of metabolic acidosis accompanied a decline in renal function [38]. The precise prevalence of metabolic acidosis exclusively instigated by CKD remains speculative.

The role of bone as a source of buffer, contributing to both the systemic $\mathrm{pH}$ homeostasis and defense against acid-base disorders is well known [39]. The skeleton of an average sized adult contains about $50,000 \mathrm{mEq}$ of calcium salts, predominantly in the form of calcium phosphate and to a lesser extent calcium carbonate. Because of its alkaline properties, the bone calcium phosphate is mobilized to supply phosphate buffer system to rectify the systemic acidosis in CKD or neutralize the acid-forming effects of diets. Over time, this may lead to bone demineralization, osteomalacia, and skeletal weakness.

A small but significant daily loss of bone calcium occurs in individuals with CKD during periods of stable acidosis, which returns to normal values when the acidosis is corrected [40]. Several studies have confirmed the loss of calcium carbonate from skeleton resulting in a negative calcium balance during metabolic acidosis in mammals $[41,42]$. Overall, these changes were proportional to the duration of the uremia and presumably the length of acidosis [43].

Metabolic acidosis in individuals with impaired kidney function is likely associated with exacerbation of secondary hyperparathyroidism by decreasing the sensitivity of PTH secretion in response to elevated ionized calcium [30]. These data suggest that metabolic acidosis may lead to the worsening of secondary hyperparathyroidism, since correction of metabolic acidosis improves the bone mineralization and histology in patients on maintenance hemodialysis [30]. Published studies suggest variable effects of metabolic acidosis on the parathyroid gland [44], with PTH levels remaining unchanged in ESRD patients treated with a high dialysate bicarbonate, but significantly increasing in patients with persistent metabolic acidosis on standard dialysate bicarbonate [45]. Additionally, the combination of metabolic acidosis and elevated se- rum $\mathrm{PTH}$ levels, as detected in patients with CKD, may lead to a greater efflux of calcium from bones compared with either metabolic acidosis or hyperparathyroidism alone [46].

Metabolic acidosis promotes an adaptive increase in ammonium excreted per nephron, which is associated with the activation of the complement system, the reninangiotensin system, and with increased renal production of endothelin-1, all of which may produce tubulointerstitial inflammation and chronic damage to the kidney [47]. The activation of renin-angiotensin system, while important for enhanced urinary acidification, may have detrimental side effects, including proteinuria [48], renal damage, and progressive CKD [48]. Given the abovementioned consequences of metabolic acidosis, the following discussion will focus on the evaluation and treatment of metabolic acidosis in CKD.

\section{Effect of Impaired $\mathrm{NH}_{4}{ }^{+}$Excretion on Systemic Acid-Base Balance}

A recently published article in the Journal of American Society of Nephrology examined the relationship of urine ammonium excretion $\left(\mathrm{uNH}_{4}^{+}\right)$in CKD with clinical outcomes [49]. The authors evaluated data from participants in the African American Study of Kidney Disease and Hypertension trial [50]. They report a positive association between lower daily $\mathrm{uNH}_{4}{ }^{+}$and higher risk of death or progression to ESRD in African American patients with hypertensive $\mathrm{CKD}$, independent of demographics, CKD severity, or the magnitude of proteinuria. In their analysis, the authors conclude that the relationship between the low $\mathrm{uNH}_{4}{ }^{+}$and progression of CKD was independent of serum bicarbonate $\left(\mathrm{tCO}_{2}\right)$ and acid-base status. Specifically, among individuals without acidosis, $\mathrm{uNH}_{4}{ }^{+}$excretion $<20$ $\mathrm{mEq} /$ day was associated with a higher risk of death or ESRD (36\%) than those with daily $\mathrm{uNH}_{4}{ }^{+}$excretion $\geq 20$ $\mathrm{mEq} /$ day. Finally, they showed that individuals with low $\mathrm{uNH}_{4}{ }^{+}$excretion had increased incidence of metabolic acidosis at 1 year, as defined by serum bicarbonate concentration of $<22 \mathrm{mEq} / \mathrm{L}$. Cumulatively, these data suggest that low daily $\mathrm{uNH}_{4}{ }^{+}$excretion portends poor prognosis in CKD individuals with regard to the development of metabolic acidosis and long-term clinical outcome.

Overall, the data are rationally presented, and the main conclusions of the manuscript are valid. We think there are several points that need to be considered in interpreting the data on the cause of altered $\mathrm{uNH}_{4}{ }^{+}$in $\mathrm{CKD}$ and its role in $\mathrm{CKD}$ outcomes. 
First, the study is limited to African Americans with hypertensive CKD and does not fully represent all CKD patients, therefore further investigations would be needed to elaborate the impact of urinary ammonium excretion on CKD progression across gender and race and other variables, such as blood pressure.

Second, a significant portion of individuals in the study $(\sim 40 \%)$ received either an angiotensin converting enzyme inhibitor (ACEI) or an angiotensin receptor blocker (ARB), which may complicate the interpretation of the data. Previous studies have shown that angiotensin II stimulates ammonia production and transport by the proximal tubule [51-53]. While the proportion of individuals receiving ACEI or ARB was comparable in all 3 groups with altered ammonium excretion rates $(\sim 40 \%)$, the possibility exist that those with the lowest $\mathrm{uNH}_{4}{ }^{+}$excretion were either on higher doses or were the most sensitive to the effect of ACEI or ARB for the control of their blood pressure, and therefore may have been affected the most with respect to $\mathrm{uNH}_{4}{ }^{+}$.

Two other variables, gender and the amount of protein intake, may have affected $\mathrm{uNH}_{4}{ }^{+}$, albeit in the opposite direction. The group with $\mathrm{uNH}_{4}{ }^{+}$excretion $\geq 20 \mathrm{mEq} /$ day had the largest daily protein intake and was predominantly men; both variables are associated with increased $\mathrm{uNH}_{4}{ }^{+}$excretion. While the authors indicate that the correlation of low $\mathrm{uNH}_{4}{ }^{+}$with the incident acidosis is independent of gender and amount of protein consumption, it should be noted that higher protein intake is associated with increased urine output due to enhanced $\mathrm{NH}_{4}{ }^{+}$production and the downregulation of AQP2 [54-56]. We have not been provided with the urine osmolality or the urine $\mathrm{pH}$ in the 3 different categories of $\mathrm{uNH}_{4}{ }^{+}$. Did the group with low $\mathrm{uNH}_{4}{ }^{+}$have a more concentrated urine and/or more acidic urine? Or was the urine $\mathrm{pH}$ more alkaline in the group with the lowest $\mathrm{uNH}_{4}^{+}$? Further, no data are provided on serum calcium or urine calcium excretion, which is increased due to enhanced bone turnover in individuals on a high protein diet and may play a role in antagonizing the action of AQP-2, ENaC and/or $\mathrm{H}^{+}$-ATPase.

It is more than several decades since Giovannetti and Maggiore proposed the use of a very low-protein (0.3-0.4 $\mathrm{g} / \mathrm{kg} /$ day) diet supplemented with essential amino acids for the management of advanced CKD [57]. Initially, the low intake of proteins was used to reduce uremic symptoms, including the generation of metabolic acidosis. The low-protein diet was largely abandoned due to multiple factors [58]. In one study, Kopple and Coburn [58] showed that the mean nitrogen balance was negative with a low-protein diet and neutral or positive with a highprotein diet. Potassium balance correlated directly with nitrogen balance, and the mean body weight increased with a higher protein diet. Moreover, with the higher protein diet, the added nitrogen was retained in a non-urea form, suggesting that a high-protein diet is nutritionally superior to a low-protein diet [58]. The Modification of Diet in Renal Disease study was the largest randomized clinical trial to test the hypothesis that protein restriction slows the progression of chronic renal disease. However, the results of that study and other trials have been inconclusive [59] with regard to the efficacy of this intervention. Since then, there have been multiple studies discussing the beneficial effect of low protein intake, however the data remain unsatisfying.

It is puzzling that while the generation of metabolic acidosis in the current study is associated with a lower protein intake (consistent with reduced $\mathrm{NH}_{4}{ }^{+}$generation in the gut and low $\mathrm{uNH}_{4}{ }^{+}$), the individuals on low-protein diet in earlier studies showed remarkable resilience to the development of acidosis. This issue raises a more fundamental question: Are we selecting a subgroup of patients that exhibit a more progressive decline in their kidney function due to factors such as increased interstitial fibrosis etc., which can also interfere with $\mathrm{NH}_{4}{ }^{+}$synthesis and excretion? In other words, does the low $\mathrm{uNH}_{4}^{+}$in the current study [2] simply reflect a more aggressive underlying kidney disease?

Lastly, the validity of NEAP as a marker of net endogenous acid production in individuals with CKD should be reevaluated. The original studies on NEAP were conducted on individuals with normal kidney function. As described, the concentration of blood glutamine, which is synthesized in the liver and competes with urea for the utilization of $\mathrm{NH}_{4}{ }^{+} / \mathrm{NH}_{3}$, changes during acidosis (and may be in $\mathrm{CKD}$ ). Additional studies examining NEAP measurement in individuals with advanced kidney dysfunction are warranted.

\section{Conclusion}

Metabolic acidosis is associated with multiple undesirable outcomes in CKD, including accelerated progression to ESRD. Assessing urine ammonium excretion may provide important predictive values in the evaluation and management of metabolic acidosis. The majority of studies correlating the low urinary $\mathrm{NH}_{4}{ }^{+}$excretion with the development and/or severity of metabolic acidosis are in subjects with normal kidney function or mild kidney dys- 
function, such as renal tubular acidosis. There are few studies examining the association of low urinary $\mathrm{NH}_{4}{ }^{+}$ excretion with metabolic acidosis in CKD. A recently published study has suggested significant relationship with lower daily $\mathrm{uNH}_{4}{ }^{+}$and higher risk of death or progression to ESRD in African American patients with hypertensive CKD [32]. We agree with the premise of that study that preemptive treatment of patients with CKD and reduced $\mathrm{uNH} 4^{+}$with alkali therapy may afford beneficial long-term protective effects against the progres- sion to ESRD. We suggest that chemistry laboratories and hospitals around the country should consider establishing tests to directly measure $\mathrm{uNH}_{4}{ }^{+}$rather than relying on physicians' estimation of urine $\mathrm{NH}_{4}{ }^{+}$excretion based on the urinary anion gap or osmolal gap calculation.

\section{Disclosure Statement}

The authors have no conflicts of interest to declare.

\section{References}

1 Warnock DG: Uremic acidosis. Kidney Int 1988;34:278-287.

2 Bailey JL: Metabolic acidosis: an unrecognized cause of morbidity in the patient with chronic kidney disease. Kidney Int Suppl 2005:S15-S23.

3 Garibotto G, Sofia A, Robaudo C, Saffioti S, Sala MR, Verzola D, et al: Kidney protein dynamics and ammoniagenesis in humans with chronic metabolic acidosis. J Am Soc Nephrol. 2004;15:1606-1615.

4 Hamm LL, Nakhoul N, Hering-Smith KS: Acid-base homeostasis. Clin J Am Soc Nephrol 2015;10:2232-2242.

5 Kraut JA, Kurtz I: Metabolic acidosis of CKD: diagnosis, clinical characteristics, and treatment. Am J Kidney Dis 2005;45:978-993.

6 Kopple JD, Kalantar-Zadeh K, Mehrotra R: Risks of chronic metabolic acidosis in patients with chronic kidney disease. Kidney Int Suppl 2005:S21-S27.

7 Welbourne T, Weber M, Bank N: The effect of glutamine administration on urinary ammonium excretion in normal subjects and patients with renal disease. J Clin Invest 1972;51: 1852-1860.

8 Widmer B, Gerhardt RE, Harrington JT, Cohen JJ: Serum electrolyte and acid base composition. The influence of graded degrees of chronic renal failure. Arch Intern Med 1979; 139:1099-1102.

9 Uribarri J, Douyon H, Oh MS: A re-evaluation of the urinary parameters of acid production and excretion in patients with chronic renal acidosis. Kidney Int 1995;47:624627.

10 Eustace JA, Astor B, Muntner PM, Ikizler TA, Coresh J: Prevalence of acidosis and inflammation and their association with low serum albumin in chronic kidney disease. Kidney Int 2004;65:1031-1040.

11 Remer T: Influence of diet on acid-base balance. Semin Dial 2000;13:221-226.

12 Lemann J Jr, Relman AS: The relation of sulfur metabolism to acid-base balance and electrolyte excretion: the effects of DL-methionine in normal man. J Clin Invest 1959;38: 2215-2223.
13 Khairallah P, Isakova T, Asplin J, Hamm L, Dobre M, Rahman M, et al: Acid load and phosphorus homeostasis in CKD. Am J Kidney Dis 2017;70:541-550.

14 Noori N, Sims JJ, Kopple JD, Shah A, Colman $S$, Shinaberger CS, et al: Organic and inorganic dietary phosphorus and its management in chronic kidney disease. Iran J Kidney Dis 2010;4:89-100.

15 Weiner ID, Verlander JW: Ammonia transporters and their role in acid-base balance. Physiol Rev 2017;97:465-494.

16 Tizianello A, Deferrari G, Garibotto G, Robaudo C, Bruzzone M, Passerone GC: Renal ammoniagenesis during the adaptation to metabolic acidosis in man. Contrib Nephrol 1982;31:40-46.

17 Tizianello A, Deferrari G, Garibotto G, Robaudo C, Acquarone N, Ghiggeri GM: Renal ammoniagenesis in an early stage of metabolic acidosis in man. J Clin Invest 1982;69:240250.

18 Squires EJ, Hall DE, Brosnan JT: Arteriovenous differences for amino acids and lactate across kidneys of normal and acidotic rats. Biochem J 1976;160:125-128.

19 Karinch AM, Lin CM, Wolfgang CL, Pan M, Souba WW: Regulation of expression of the SN1 transporter during renal adaptation to chronic metabolic acidosis in rats. Am J Physiol Renal Physiol 2002;283:F1011F1019.

20 Bobulescu IA, Moe OW: Na+/H+ exchangers in renal regulation of acid-base balance. Semin Nephrol 2006;26:334-344.

21 Tanner GA: Renal regulation of acid-base balance: ammonia excretion. Physiologist 1984; 27:95-97.

22 Soleimani M, Rastegar A: Pathophysiology of renal tubular acidosis: core curriculum 2016. Am J Kidney Dis 2016;68:488-498.

23 Wagner CA, Devuyst O, Belge H, Bourgeois S, Houillier P: The rhesus protein RhCG: a new perspective in ammonium transport and distal urinary acidification. Kidney Int 2011; 79:154-161.

24 Handlogten ME, Osis G, Lee HW, Romero MF, Verlander JW, Weiner ID: NBCe1 ex- pression is required for normal renal ammonia metabolism. Am J Physiol Renal Physiol 2015;309:F658-F666.

25 Soleimani M, Burnham CE: Physiologic and molecular aspects of the $\mathrm{Na}+\mathrm{HCO} 3$ - cotransporter in health and disease processes. Kidney Int 2000;57:371-384.

26 Galla JH: Metabolic alkalosis. J Am Soc Nephrol 2000;11:369-375.

27 Sartorius OW, Roemmelt JC, Pitts RF, Calhoon D, Miner P: The renal regulation of acid-base balance in man. IV. The nature of the renal compensations in ammonium chloride acidosis. J Clin Invest 1949;28:423-439.

28 Green J, Kleeman CR: Role of bone in regulation of systemic acid-base balance. Kidney Int 1991;39:9-26.

29 Franch HA, Mitch WE: Catabolism in uremia: the impact of metabolic acidosis. J Am Soc Nephrol 1998;9 (12 suppl):S78-S81

30 Graham KA, Hoenich NA, Tarbit M, Ward MK, Goodship TH: Correction of acidosis in hemodialysis patients increases the sensitivity of the parathyroid glands to calcium. J Am Soc Nephrol 1997;8:627-631.

31 Kovesdy CP, Anderson JE, Kalantar-Zadeh K: Association of serum bicarbonate levels with mortality in patients with non-dialysis-dependent CKD. Nephrol Dial Transplant 2009; 24:1232-1237.

32 Bommer J, Locatelli F, Satayathum S, Keen ML, Goodkin DA, Saito A, et al: Association of predialysis serum bicarbonate levels with risk of mortality and hospitalization in the dialysis outcomes and practice patterns study (DOPPS). Am J Kidney Dis 2004;44:661-671.

33 Shah SN, Abramowitz M, Hostetter TH, Melamed ML: Serum bicarbonate levels and the progression of kidney disease: a cohort study. Am J Kidney Dis 2009;54:270-277.

34 Menon V, Tighiouart H, Vaughn NS, Beck GJ, Kusek JW, Collins AJ, et al: Serum bicarbonate and long-term outcomes in CKD. Am J Kidney Dis 2010;56:907-914.

35 Hsu CY, Chertow GM: Elevations of serum phosphorus and potassium in mild to moderate chronic renal insufficiency. Nephrol Dial Transplant 2002;17:1419-1425. 
36 Coresh J, Astor BC, Greene T, Eknoyan G, Levey AS: Prevalence of chronic kidney disease and decreased kidney function in the adult US population: third National health and nutrition examination survey. Am J Kidney Dis 2003;41:1-12.

37 Frassetto L, Sebastian A: Age and systemic acid-base equilibrium: analysis of published data. J Gerontol A Biol Sci Med Sci 1996;51: B91-B99.

38 Frassetto LA, Morris RC Jr, Sebastian A: Effect of age on blood acid-base composition in adult humans: role of age-related renal functional decline. Am J Physiol 1996;271(6 pt 2): F1114-F1122.

39 New SA: Nutrition society medal lecture. The role of the skeleton in acid-base homeostasis. Proc Nutr Soc 2002;61:151-164.

40 Litzow JR, Lemann J Jr, Lennon EJ: The effect of treatment of acidosis on calcium balance in patients with chronic azotemic renal disease. J Clin Invest 1967;46:280-286.

41 Jaffe HL, Bodansky A, Chandler JP: Ammonium chloride decalcification, as modified by calcium intake: the relation between generalized osteoporosis and ostitis fibrosa. J Exp Med 1932;56:823-834.

42 Burnell JM: Changes in bone sodium and carbonate in metabolic acidosis and alkalosis in the dog. J Clin Invest 1971;50:327-331.

43 Pellegrino ED, Biltz RM: The composition of human bone in uremia. Observations on the reservoir functions of bone and demonstration of a labile fraction of bone carbonate. Medicine (Baltimore) 1965;44:397418.
44 Coe FL, Firpo JJ Jr, Hollandsworth DL, Segil L, Canterbury JM, Reiss E: Effect of acute and chronic metabolic acidosis on serum immunoreactive parathyroid hormone in man. Kidney Int 1975;8:263-273.

45 Lefebvre A, de Vernejoul MC, Gueris J, Goldfarb B, Graulet AM, Morieux C: Optimal correction of acidosis changes progression of dialysis osteodystrophy. Kidney Int 1989;36: 1112-1118.

46 Bushinsky DA, Nilsson EL: Additive effects of acidosis and parathyroid hormone on mouse osteoblastic and osteoclastic function. Am J Physiol 1995;269(6 pt 1):C1364-C1370.

47 Frassetto LA, Hsu CY: Metabolic acidosis and progression of chronic kidney disease. J Am Soc Nephrol 2009;20:1869-1870.

$48 \mathrm{Ng} \mathrm{HY}$, Chen HC, Tsai YC, Yang YK, Lee CT: Activation of intrarenal renin-angiotensin system during metabolic acidosis. Am J Nephrol 2011;34:55-63.

49 Raphael KL, Carroll DJ, Murray J, Greene T, Beddhu S: Urine ammonium predicts clinical outcomes in hypertensive kidney disease. J Am Soc Nephrol 2017;28:2483-2490.

50 Wright JT Jr, Kusek JW, Toto RD, Lee JY, Agodoa LY, Kirk KA, et al: Design and baseline characteristics of participants in the African American Study of Kidney Disease and Hypertension (AASK) Pilot Study. Control Clin Trials 1996;17(4 suppl):3S$16 \mathrm{~S}$.

51 Chobanian MC, Julin CM: Angiotensin II stimulates ammoniagenesis in canine renal proximal tubule segments. Am J Physiol 1991; 260(1 pt 2):F19-F26.
52 Nagami GT: Effect of angiotensin II on ammonia production and secretion by mouse proximal tubules perfused in vitro. J Clin Invest 1992;89:925-931.

53 Nagami GT: Effect of luminal angiotensin II on ammonia production and secretion by mouse proximal tubules. Am J Physiol 1995; 269(1 pt 2):F86-F92.

54 Lauridsen TG, Vase H, Starklint J, Bech JN, Pedersen EB: Protein-enriched diet increases water absorption via the aquaporin-2 water channels in healthy humans. Nephrol Dial Transplant 2010;25:2502-2510.

55 Sands JM, Naruse M, Jacobs JD, Wilcox JN Klein JD: Changes in aquaporin-2 protein contribute to the urine concentrating defect in rats fed a low-protein diet. J Clin Invest 1996;97:2807-2814.

56 Elfers K, Breves G, Muscher-Banse AS: Modulation of aquaporin 2 expression in the kidney of young goats by changes in nitrogen intake. J Comp Physiol B 2014;184:929-936.

57 GiovannettiS, Maggiore Q: Alow-nitrogen diet with proteins of high biological value for severe chronic uraemia. Lancet 1964;1:1000-1003.

58 Kopple JD, Coburn JW: Metabolic studies of low protein diets in uremia. I. Nitrogen and potassium. Medicine (Baltimore) 1973;52: 583-595.

59 Levey AS, Greene T, Beck GJ, Caggiula AW, Kusek JW, Hunsicker LG, et al: Dietary protein restriction and the progression of chronic renal disease: what have all of the results of the MDRD study shown? Modification of diet in renal disease study group. J Am Soc Nephrol 1999;10:2426-2439. 